\title{
INFLUENCE OF SUBSTITUENTS ON BOND LENGTHS
}

\author{
H. HAYD, H. SAVIN, A. STOLL and H. PREUSS
}

Institut für Theoretische Chemie, Universität Stuttgart, Pfaffenwaldring 55, D-7000 Stuttgart 80 (F.R.G.)

\section{G. BECKER}

Institut für Anorganische Chemie, Universität Stuttgart, Pfaffenwaldring 55, D-7000 Stuttgart 80 (F.R.G.)

(Received 27 July 1987)

\section{ABSTRACT}

Pseudopotential SCF calculations for $\mathrm{Y}_{3} \mathrm{C}-\mathrm{X}, \mathrm{Y}=\mathrm{H}, \mathrm{F} ; \mathrm{X}=\mathrm{H}, \mathrm{F}, \mathrm{Cl}, \mathrm{PH}_{2}, \mathrm{PF}_{2}$ and a simple model, simulating the substituents by a homogeneous, electric field, are presented in order to rationalize the substitution effect on the $\mathrm{C}-\mathrm{X}$ bond.

\section{INTRODUCTION}

A bond will change its length, if the substitution of the bonded atoms alters. It has been observed $[1,2]$ that substitution by electronegative atoms or groups often shortens the neighboring bonds.

Marsden attempted to explain the "curious striking trends" [3] in $\left(\mathrm{F}_{3}\right) \mathrm{C}-\mathrm{X}$ bond distances, which are shorter than $\left(\mathrm{H}_{3}\right) \mathrm{C}-\mathrm{X}$ if $\mathrm{X}$ is highly electronegative but longer if $\mathrm{X}$ is of moderate or low electronegativity.

Oberhammer [4] investigated a series of methyl- and tri-fluoromethyl-compounds by gas phase electron diffraction: $\left(\mathrm{H}_{3} \mathrm{C}\right)_{n}-\mathrm{X}$ and $\left(\mathrm{F}_{3} \mathrm{C}\right)_{n}-\mathrm{X} ; \mathrm{X}=\mathrm{H}, \mathrm{F}$, $\mathrm{Cl}, \mathrm{Br}, \mathrm{I}, \mathrm{Se}, \mathrm{S}, \mathrm{O}, \mathrm{P}, \mathrm{As} ; n=1,2,3$. He found a linear correlation between the shortening of the $\mathrm{C}-\mathrm{X}$ bond due to $\mathrm{CH}_{3} / \mathrm{CF}_{3}$ substitution and the electronegativity of $\mathrm{X}$. To explain this, he used a rather simple electrostatic model [5]. The three fluorine atoms in $\mathrm{CF}_{3}$ polarize the carbon atom; it carries a high positive net charge. If $\mathrm{X}$ is also of high electronegativity, and partially negative as well, the two neighbouring charges of opposite sign will shorten the bond by their classical electrostatic interaction.

This substitution effect will be examined herein by means of pseudopotential calculations for $\mathrm{Y}_{3} \mathrm{C}-\mathrm{X}, \mathrm{Y}=\mathrm{H}, \mathrm{F} ; \mathrm{X}=\mathrm{H}, \mathrm{F}, \mathrm{Cl}, \mathrm{PH}_{2}, \mathrm{PF}_{2}$ and interpreted by using valence-density plots. Additionally we shall present a quite simple but useful model for analyzing and rationalizing the substitution effect. 
Our pseudopotentials have been extensively discussed in previous papers [6-10]; therefore, we shall just briefly repeat some basic features. The atomic cores are approximated in our approach by semilocal pseudopotentials of the form

$$
V_{s p}^{\mu}(r)=-\frac{Q^{\mu}}{r_{i}}+\sum_{l} B_{l}^{\mu} e^{-\beta_{l}^{\mu} r^{2}} \hat{P}_{l}^{\mu}
$$

where $r$ stands for the electronic coordinate, $Q^{\mu}$ is the core charge of atom $\mu$, $P_{l}^{\mu}$ is the projector on the angular symmetry $l$ around core $\mu$ and the parameters $B_{l}^{\mu}$ and $\beta_{l}^{\mu}$ are adjusted to experimental atomic energies (ionization and excitation energies). For each symmetry, one pair of parameters [11], listed in Table 1, yields satisfactory results [12].

With these pseudopotentials [13], we performed valence SCF calculations. The basis sets used were of Gaussian type and were obtained as follows. Starting from a $4 s, 4 p$ valence basis set, energy optimized on atomic level by pseudopotential calculations [15], two contracted sets were derived, which can be designated as (4/4) and (31/31). The basis sets were augmented by diffuse $s-, p$-functions [16] and a polarization function [17] on each atom, denoted by + and ${ }^{*}$ respectively [18].

The geometries were determined as follows. For the pentaatomic molecules, all bond lengths were optimized keeping the dihedral angle fixed. The geometry of the phosphorus compounds was determined in two steps. The geometries of $\mathrm{CH}_{3}, \mathrm{CF}_{3}$ and $\mathrm{PH}_{2}, \mathrm{PF}_{2}$ were taken from $\mathrm{CH}_{4}, \mathrm{CF}_{4}$ and from the completely optimized $\mathrm{PH}_{3}, \mathrm{PF}_{3}$ respectively. Then the fragments were put together and the bond length and the rotation around the $\mathrm{P}-\mathrm{C}$ axis were determined.

The pseudopotential calculations for atoms were performed with MEFIT [19]; the MCDF calculations, supporting atomic reference values, with MCDF [20]. For the molecular calculations, in a one-determinant-approximation, the program MELD [21] was used. The semiempirical results were produced with the MNDO/2 [22] program MOPAC [23].

TABLE 1

Pseudopotential parameters for C, F, P, Cl (from ref. 11)

\begin{tabular}{llrrrrr}
\hline & \multicolumn{1}{l}{$B_{0}$} & \multicolumn{1}{c}{$\beta_{0}$} & \multicolumn{1}{c}{$B_{1}$} & \multicolumn{1}{c}{$\beta_{1}$} & \multicolumn{1}{c}{$B_{2}$} & $\beta_{2}$ \\
\hline $\mathrm{C}$ & 37.4565 & 6.8446 & -2.6739 & 7.9317 & & \\
$\mathrm{~F}$ & 96.2419 & 16.7628 & -4.5819 & 19.8576 & & \\
$\mathrm{P}$ & 35.2261 & 3.3603 & 17.6041 & 2.7681 & -5.7899 & 3.487 \\
$\mathrm{Cl}$ & 54.7218 & 4.7957 & 29.6573 & 4.2155 & -8.0060 & 5.338 \\
\hline
\end{tabular}




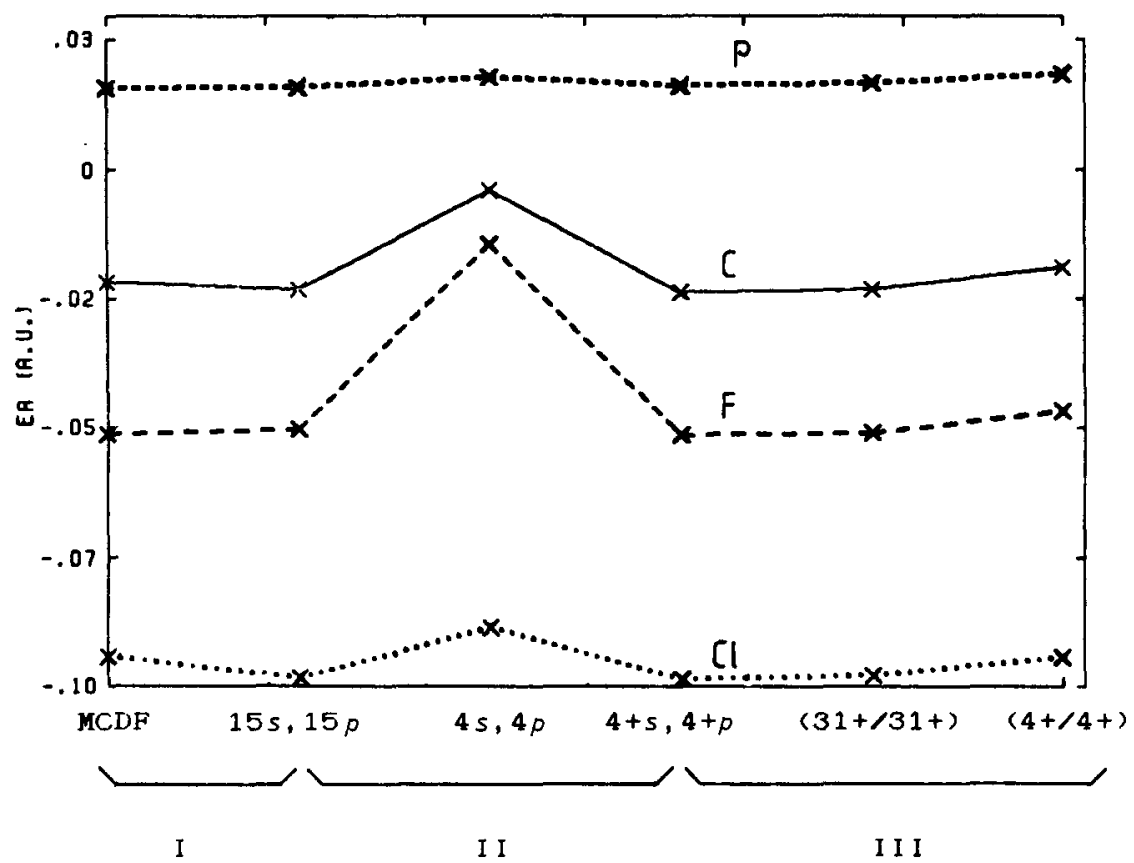

Fig. 1. Electron affinity from the MCDF calculations and the pseudopotential calculations using different basis sets. The plot shows how the pseudopotential (I), the size of the basis set (II) and its contraction (III) affects the electron affinity.

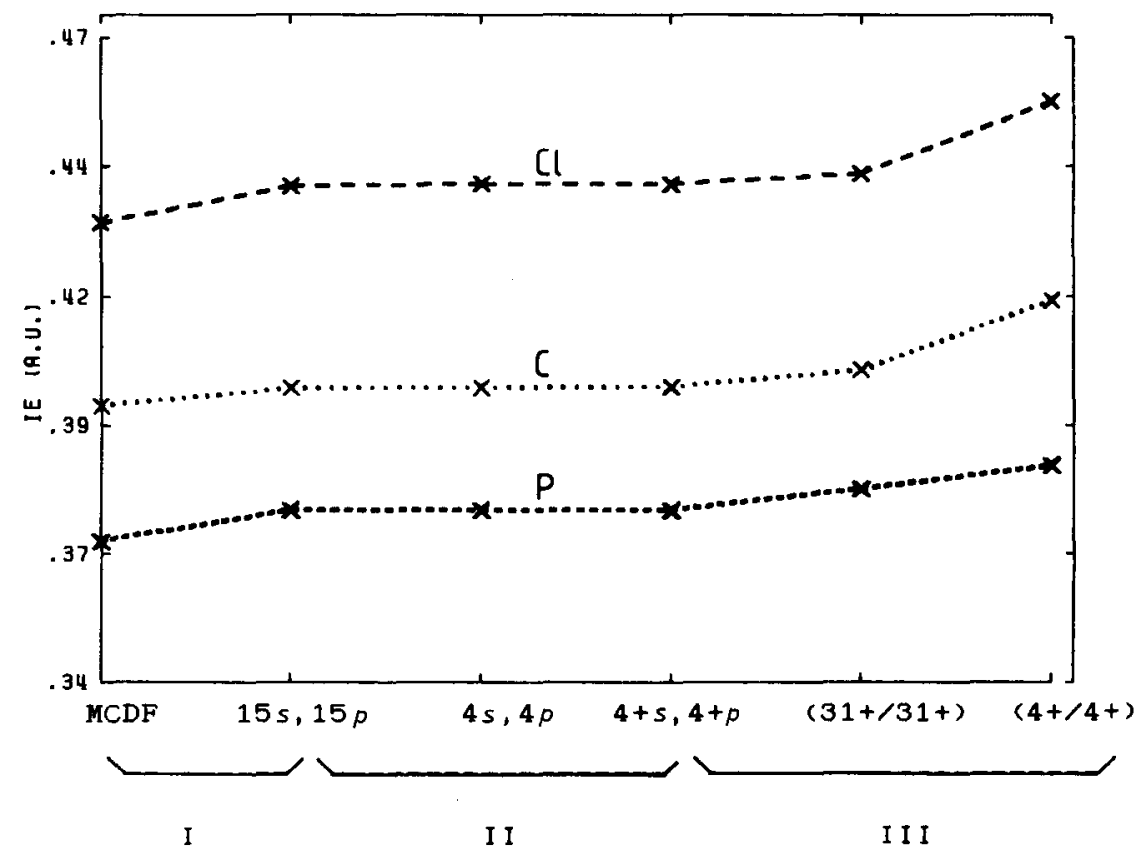

Fig. 2. Ionization energy from the MCDF calculations and the pseudopotential calculations using different basis sets. The plot shows how the pseudopotential (I), the size of the basis set (II) and its contraction (III) affects the ionization energy. (Results for F have been omitted, since they are irrelevant for the molecular calculations, $\mathrm{F}$ being the most electronegative atom.) 


\section{TABLE 2}

$\mathrm{C}-\mathrm{H}$ bond lengths $(\mathrm{pm})$, calculated with various basis sets and methods and the experimental values. The change with respect to $\mathrm{CH}_{4}$ is given in parentheses

\begin{tabular}{|c|c|c|c|c|}
\hline & $\mathrm{H}_{3} \mathrm{C}-\mathrm{H}$ & $\mathrm{ClH}_{2} \mathrm{C}-\mathrm{H}$ & $\mathrm{FH}_{2} \mathrm{C}-\mathrm{H}$ & $\mathrm{F}_{3} \mathrm{C}-\mathrm{H}$ \\
\hline$(4 / 4)$ & 113 & $\begin{array}{l}113 \\
(0)\end{array}$ & $\begin{array}{r}114 \\
(+1)\end{array}$ & $\begin{array}{r}117 \\
(+4)\end{array}$ \\
\hline$(31 / 31)$ & 108 & $\begin{array}{l}108 \\
(0)\end{array}$ & $\begin{array}{r}107 \\
(-1)\end{array}$ & $\begin{array}{r}106 \\
(-2)\end{array}$ \\
\hline$(31+/ 31+)$ & 108 & $\begin{array}{l}108 \\
(0)\end{array}$ & $\begin{array}{r}107 \\
(-1)\end{array}$ & $\begin{array}{r}106 \\
(-2)\end{array}$ \\
\hline$(31 / 31)^{*}$ & 108 & $\begin{array}{l}108 \\
(0)\end{array}$ & $\begin{array}{r}108 \\
(-1)\end{array}$ & $\begin{array}{r}107 \\
(-1)\end{array}$ \\
\hline$(31+/ 31+)^{*}$ & 108 & $\begin{array}{r}108 \\
(-1)\end{array}$ & $\begin{array}{r}108 \\
(-1)\end{array}$ & $\begin{array}{r}107 \\
(-1)\end{array}$ \\
\hline $\mathrm{MNDO} / 2$ & 110 & ${ }_{(0)}^{110}$ & $\begin{array}{r}112 \\
(+1)\end{array}$ & $\begin{array}{r}114 \\
(+4)\end{array}$ \\
\hline STO-3G & $108^{a}$ & $\begin{array}{c}109^{b} \\
(+1)\end{array}$ & $\begin{array}{c}110^{a} \\
(+1)\end{array}$ & $\begin{array}{c}112^{\mathrm{a}} \\
(+4)\end{array}$ \\
\hline $3-21 G$ & $108^{b}$ & $\begin{array}{c}107^{\mathrm{b}} \\
(-1)\end{array}$ & $(0)^{108^{b}}$ & $\begin{array}{c}107^{\mathbf{b}} \\
(-2)\end{array}$ \\
\hline $6-31 G^{*}$ & $108^{c}$ & & $\begin{array}{l}108^{b} \\
(0)\end{array}$ & \\
\hline Exp. & $109^{d}$ & $\begin{array}{l}109^{e} \\
(0)\end{array}$ & $(0)=$ & $(0)^{110^{8}}$ \\
\hline
\end{tabular}

${ }^{\mathrm{a}} \operatorname{Ref} .26 .{ }^{\mathrm{b}} \operatorname{Ref} .27 .{ }^{\mathrm{c}} \operatorname{Ref} .28 .{ }^{\mathrm{d}} \operatorname{Ref} .29 .{ }^{\mathrm{e}} \operatorname{Ref} .30 .{ }^{\mathrm{f}} \operatorname{Ref} .31 .{ }^{\mathrm{g}} \operatorname{Ref} .32$.

\section{RESULTS AND DISCUSSION}

Firstly, some atomic results are given, in order to characterize the quality of the pseudopotentials and basis sets.

For the first excitation energy, the ionization energy, and the electron affinity, the maximum error caused by pseudopotential amounts to 0.008 a.u. (first excitation energy of carbon ), the average error is 0.004 a.u.

The influence of the contraction of the basis set is shown in Figs. 1 and 2.

The main error in the electron affinity arises from the neglect of the diffuse function, as may be seen from Fig. 1. The error is larger for the elements of the second row than for those of the third.

In contrast to the electron affinity, the ionization energy is virtually uninfluenced by the reduction of the basis set and the largest errors arise from the $(4 / 4)$ contraction, as may be seen from Fig. 2.

As expected, the first excitation energy was found to be even less affected by the size or contraction of the basis set than the ionization energy.

Following these tests of the pseudopotentials and basis sets on the atomic level, the molecular calculations are now presented. Tables $2-4$ show our 
TABLE 3

C-F bond lengths (pm), calculated with various basis sets and methods and the experimental values. The change with respect to $\mathrm{CH}_{3}-\mathrm{F}$ is given in parentheses.

\begin{tabular}{lcccc}
\hline & $\mathrm{H}_{3} \mathrm{C}-\mathrm{F}$ & $\mathrm{F}_{2} \mathrm{HC}-\mathrm{F}$ & $\mathrm{ClF}_{2} \mathrm{C}-\mathrm{F}$ & $\mathrm{F}_{3} \mathrm{C}-\mathrm{F}$ \\
\hline$(4 / 4)$ & 150 & 147 & 147 & 147 \\
$(31 / 31)$ & & $(-3)$ & $(-3)$ & $(-3)$ \\
$(31+/ 31+)$ & 141 & 136 & 134 & 134 \\
$(31 / 31)^{*}$ & 141 & 136 & $(-7)$ & $(-7)$ \\
& 135 & $(-6)$ & $(-7)$ & 134 \\
$(31+/ 31+)^{*}$ & 135 & $(-5)$ & 130 & $(-8)$ \\
& & 130 & 130 & $(-6)$ \\
MNDO/2 & 135 & $(-5)$ & $(-6)$ & $(-6)$ \\
& & 135 & 134 & 135 \\
STO-3G & $138^{\mathrm{b}}$ & $10)$ & $(-1)$ & $137^{\mathrm{b}}$ \\
$3-21 \mathrm{G}$ & $140^{\mathrm{b}}$ & $(-1)$ & & $(-2)$ \\
& $136^{\mathrm{b}}$ & $135^{\mathrm{b}}$ & & $133^{\mathrm{b}}$ \\
6-31G* & $138^{\mathrm{f}}$ & $(-6)$ & & $(-8)$ \\
Exp. & & $133^{\mathrm{g}}$ & $133^{\mathrm{h}}$ & $132^{\mathrm{i}}$ \\
& & $(-5)$ & $(-5)$ & $(-6)$ \\
\hline
\end{tabular}

a,b,c,d,e,f,z References as in Table 2. ${ }^{\text {h }}$ Ref. 33 . ${ }^{\text {inef. }} 4$.

TABLE 4

$\mathrm{C}-\mathrm{Cl}$ bond lengths (pm), calculated with various basis sets and methods and the experimental values. The change with respect to $\mathrm{CH}_{3}-\mathrm{Cl}$ is given in parentheses.

\begin{tabular}{llr}
\hline & $\mathrm{H}_{3} \mathrm{C}-\mathrm{Cl}$ & $\mathrm{F}_{3} \mathrm{C}-\mathrm{Cl}$ \\
\hline$(4 / 4)$ & 191 & $\begin{array}{r}196 \\
(+5) \\
179\end{array}$ \\
$(31 / 31)$ & 184 & $\begin{array}{r}178 \\
178\end{array}$ \\
$(31+/ 31+)$ & 183 & $\begin{array}{r}175 \\
(-2)\end{array}$ \\
$(31 / 31)^{*}$ & 178 & $\begin{array}{r}175 \\
(-3)\end{array}$ \\
$(31+/ 31+)^{*}$ & 178 & 185 \\
& & $(-6)$ \\
MNDO/2 & 179 & \\
STO-3G & $181^{\text {b }}$ & \\
3-21G & $190^{\mathrm{b}}$ & \\
6-31G* & $179^{\mathrm{e}}$ & $175^{\mathrm{h}}$ \\
Exp. & & $(-3)$ \\
\hline
\end{tabular}

b,e,h References as in Tables 2, 3 . 


\section{TABLE 5}

C-P bond lengths (pm), calculated with various basis sets and methods and the experimental values. The change with respect to $\mathrm{CH}_{3}-\mathrm{PH}_{2}$ is given in parentheses.

\begin{tabular}{llcc}
\hline & $\mathrm{H}_{3} \mathrm{C}-\mathrm{PH}_{2}$ & $\mathrm{~F}_{3} \mathrm{C}-\mathrm{PH}_{2}$ & $\mathrm{H}_{3} \mathrm{C}-\mathrm{PF}_{2}$ \\
\hline$(31 / 31)$ & 192 & 193 & 186 \\
& & $(+1)$ & $(-6)$ \\
$(31+/ 31+)^{*}$ & 186 & 188 & 182 \\
& & $(+2)$ & $(-5)$ \\
MNDO/2 & 175 & 187 & 181 \\
& & $(+12)$ & $(+6)$ \\
STO-3G & $185^{\mathrm{k}}$ & $191^{\mathrm{k}}$ & \\
$3-21 \mathrm{G}$ & $191^{1}$ & $(+6)$ & \\
$3-21 \mathrm{G}^{*}$ & $186^{\mathrm{n}}$ & $(-1)$ & \\
& $186^{\mathrm{m}}$ & $(-1)$ & $190^{\mathrm{n}}$ \\
Exp. & & $(+4)$ \\
\end{tabular}

${ }^{\mathrm{k}}$ Ref. 34. ${ }^{\mathrm{I}}$ Ref. $35 .{ }^{\mathrm{m}}$ Ref. $36 .{ }^{\mathrm{n}}$ Ref. $3 .{ }^{\circ}$ Ref. 37.
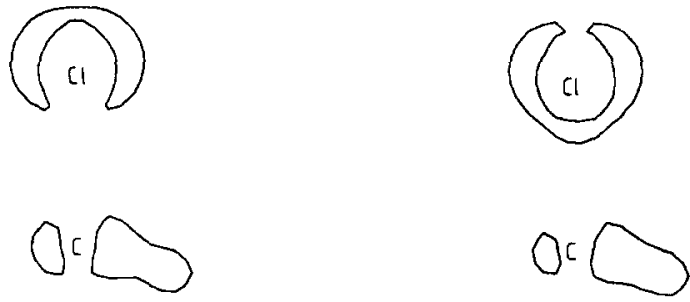

Fig. 3. Contour plots of the valence density of $\mathrm{CH}_{3} \mathrm{Cl}$ in the $\mathrm{Cl}-\mathrm{C}-\mathrm{H}$ plane calculated without (left) and with polarization functions. Contour value in a.u.: 0.23 .

results for the $\mathrm{C}-\mathrm{X}$ bond length $(\mathrm{X}=\mathrm{H}, \mathrm{F}, \mathrm{Cl})$ and the substitution effect as a function of the basis set, the experimental values and additionally some results from all-electron and MNDO/2 calculations.

For the phosphorus compounds presented in Table 5, only the $(31 / 31)$ and the best, the $(31+/ 31+)^{*}$, basis sets were used. What conclusions can be drawn from these calculations?

Basis set effects

An improvement of the basis set mostly shortens the bond length. This trend also holds when going from the minimal to the split basis set, in contrast to 


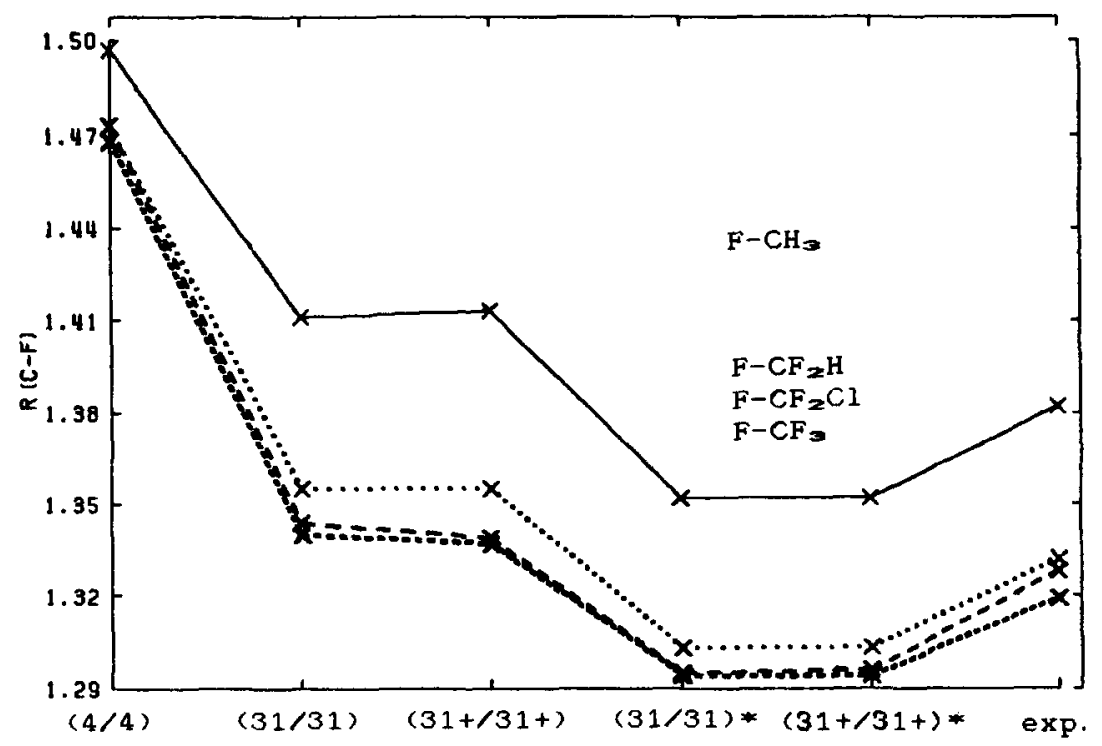

Fig. 4. C-F bond length as a function of the basis set and the experimental value. Already, a $(31 / 31)$ basis set describes the substitution effect correctly.

\section{TABLE 6}

Bond shortening $(\mathrm{pm})$ in methane and its derivatives by an external, homogeneous field of 0.028 a.u.

\begin{tabular}{ll}
\hline Bond & Shortening \\
\hline C-H & -0.07 \\
C-F & -3.23 \\
C-Cl & -1.91 \\
\hline
\end{tabular}
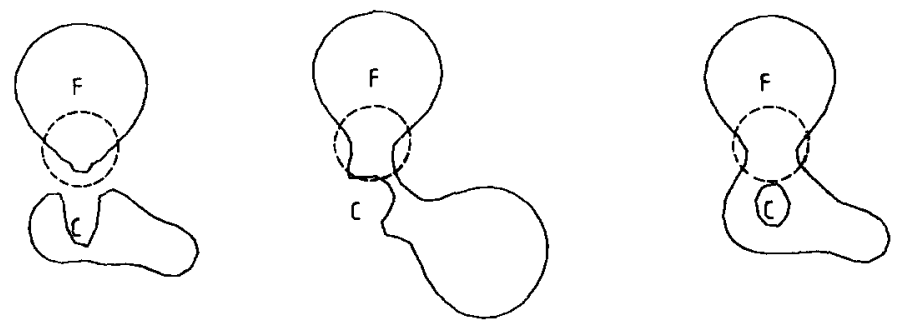

Fig. 5. Contour plots of the valence density of $\mathrm{CH}_{3} \mathrm{~F}, \mathrm{CF}_{4}$ and $\mathrm{CH}_{3} \mathrm{~F}$ with an external field of 0.028 a.u. in the F-C-X plane (from left). Contour value in a.u.: 0.23 . The external field causes a charge shift in the bond region (circled). 
TABLE 7

$\mu^{\prime} / k$ (a.u.) of the $\mathrm{X}-\mathrm{C}$ bond for $\mathrm{H}-\mathrm{CH}_{3}, \mathrm{~F}-\mathrm{CH}_{3}, \mathrm{Cl}-\mathrm{CH}_{3}$

\begin{tabular}{ll} 
Molecule & $\mu^{\prime} / k$ \\
\hline $\mathrm{H}-\mathrm{CH}_{3}$ & -0.482 \\
$\mathrm{~F}-\mathrm{CH}_{3}$ & -2.392 \\
$\mathrm{Cl}-\mathrm{CH}_{3}$ & -2.918 \\
\hline
\end{tabular}

the trend observed in all-electron calculations when going from STO-3G to 6$31 \mathrm{G}[24]$.

The most essential improvement results from splitting the basis. Diffuse functions are of no importance for the molecules treated here. The polarization functions shorten the bonds in all cases with the exception of the $\mathrm{C}-\mathrm{H}$ bond. Without (with) polarization functions, the calculations yield bond lengths which are too long (too short) compared to experiment. This is well known from all-electron calculations [25]. With one polarization function per atom, the absolute bond lengths of compounds with atoms of the third row are more accurate than those of the second row compounds. The comparison of the valence densities built up from pseudo-orbitals shows that polarization functions always have the same effect: they transfer charge from the outer sphere to the bond region. Two typical density plots in Fig. 3 demonstrate what was found for all the molecules [12].

\section{Substitution effect}

For the $\mathrm{C}-\mathrm{F}, \mathrm{C}-\mathrm{Cl}$ and $\mathrm{C}-\mathrm{P}$ bond lengths, our calculations with the $(31+/ 31+)^{*}$ basis set show trends which are in excellent agreement with the experimental substitution effects.

The $\mathrm{C}-\mathrm{H}$ bond lengths, however, are very similar, and our calculations show that the substitution effect is small, but they do not give the correct relative order here.

The completely contracted basis $(4 / 4)$, which is comparable to STO-3G cannot even catch the substitution effect at all, but a (31/31) basis describes the substitution effect adequately. This is shown in Tables 2-5 and Fig. 4 in the example of the $\mathrm{C}-\mathrm{F}$ bond.

$\mathrm{MNDO} / 2$ is not suited to investigating the substitution effect. The change in the $\mathrm{C}-\mathrm{F}$ bond is underestimated, that in the $\mathrm{C}-\mathrm{H}$ and $\mathrm{C}-\mathrm{P}$ bond is overestimated.

After demonstrating that pseudopotentials and a (31/31) basis set are suitable to describe the substitution effect in a qualitatively correct way, with an accuracy of at least $3 \mathrm{pm}$, we now try to get some more insight. For this purpose a rather simple model based on the following observations is introduced. In all 
the cases calculated here, a bond is shortened when the hydrogen of the more electropositive bond partner is substituted by a more electronegative atom or group. The change of the bond length is always connected with a shift of the electron density in the bond region [12]. The shift and hence the substitution can be simulated by exposing the non-substituted hydrogen compound to an external, homogeneous, electric field.

Table 6 shows how a field changes the bond length. The bond shortening brought about by the homogeneous field in the series $\mathrm{C}-\mathrm{H}, \mathrm{C}-\mathrm{F}, \mathrm{C}-\mathrm{Cl}$, shows the same trend, with nearly the same ratio, as that effected by substituents (see Tables 2-4). A stronger field mostly causes a stronger change as long as the field is not too strong. Figure 5 shows for $\mathrm{CH}_{3}-\mathrm{F}$ that the external field deforms the valence-density along the $\mathrm{C}-\mathrm{F}$ bond in the same way as fluorine atoms substituted for the hydrogens. This further test for the model holds for all other bonds too [12].

The interaction between a molecule and an external field is given by

$$
\begin{array}{ccr}
E=E_{0}+\frac{1}{2} k(\Delta R)^{2} & -\mu F \\
\text { I } & \text { II } & \text { III }
\end{array}
$$

I: energy of the undisturbed system

II: energy for changing the bond length

$k$ : force constant

$\Delta R$ : change of bond length by the field

III: dipole-field interaction

$\mu$ : dipole moment

$F$ : field strength

The change of bond length by the field can be calculated from the condition

$\mathrm{d} E / \mathrm{d} \Delta R=k \Delta R-\mathrm{d} \mu / \mathrm{d} \Delta R \cdot \mathrm{F}=0$

In eqn. (3), the relaxation of the electron cloud is neglected. The second term in eqn. (3) is well known from Raman spectroscopy. The effect of the relaxation on the change of bond length amounts to $0.3 \mathrm{pm}$ for the $\mathrm{C}-\mathrm{F}$ bond and to $2 \mathrm{pm}$ for the $\mathrm{C}-\mathrm{Cl}$ bond, if the field strength is 0.028 a.u. The relaxation of the softer chlorine is larger of course.

With eqn. (3) the change of bond length due to substitution is

$\Delta R \sim\left(\mu^{\prime} / k\right) \cdot F \quad$ with $\mu^{\prime}=\mathrm{d} \mu / \mathrm{d} \Delta R=\mathrm{d} \mu / \mathrm{d} R$

The calculation of $\mu^{\prime} / k$ for methane and its derivatives (see Table 7) indicates that eqn. (4) is useful despite the approximations made. The $\mathrm{C}-\mathrm{H}$ bond is considerably less changed than the carbon halogen bond by the external field, and this is correctly reflected in the different order of magnitude of $\mu^{\prime} / k$. However, since the molecules are treated as dipoles ignoring relaxation, $\mathrm{ClCH}_{3}$ has a larger value of $\mu^{\prime} / k$ but a smaller substitution effect than $\mathrm{FCH}_{3}$. 
This model can also be used in a more qualitative way, if one assumes that the dipole moment of a molecule will increase when lengthening a bond. This is correct near the equilibrium distance in most cases. Accordingly a polar bond is more affected by substitution than a homeopolar one. Substitution will shorten (lengthen) a bond if the substituents can be simulated within our model by a field, which is parallel (antiparallel) to the bond dipole. A stronger field corresponding to a more electronegative substituent will cause a stronger change. See Table 3 for example, where more and more electronegative atoms are bonded to carbon. Finally one can use our model for giving foundation to Oberhammer's simple model of interacting point charges. Calculating the classical dipole moment

$\mu=q \cdot l$

one gets

$\mu^{\prime}=q$

According to eqn. (4) $\mu^{\prime}$ is proportional to $\Delta R$. The model of the dipole-field interaction connects the change of the bond length with $\mu^{\prime}$, and (6) shows the equivalence with $q$, the quantity used by Oberhammer to explain the substitution effect.

However, we cannot quantitatively confirm Oberhammer's simple model on the basis of our computed atomic charges. According to his model, there should exist a correlation between the product of the gross atomic populations of the bonded atoms and their bond length. We do not find such a correlation in our calculations, neither by the Mulliken nor by the Löwdin population analysis.

\section{CONCLUSIONS}

Pseudopotentials allow a correct description of the substitution effect at the SCF level. A split valence (31/31) basis set is found to give good results.

In order to model the substitution effect, the substituents can be simulated by an external, homogeneous, electrostatic field.

The dependency of the bond length on the substituents or the field respectively, can be further approximated by the interaction between a dipole and a field. Rough predictions and an explanation of Oberhammer's experimental results are possible.

\section{REFERENCES}

1 C.J. Marsden and L.S. Bartell, Inorg. Chem., 15 (1976) 2713.

2 A. Yokozeki and S.H. Bauer, Top. Curr. Chem., 53 (1975) 71.

3 C.J. Marsden, Inorg. Chem., 23 (1984) 1703.

4 H. Oberhammer, J. Fluorine Chem., 23 (1983) 147. 
11 G. Igel-Mann, Arbeitsbericht des Instituts für Theoretische Chemie, 26 (1987) 5, Stuttgart, West Germany.

12 H. Hayd, Diplomarbeit, 1986, Stuttgart, West Germany.

13 For the description of the substitution effect, a core polarization potential [14] proved not to be necessary [12].

14 P. Fuentealba, Doktorarbeit, 1984, Stuttgart, West Germany.

15 Calculs Atomiques et Moleculaires Ab Initio, Manuel d'utilisation prepare a l'occasion de l'Atelier d'Initiation aux Techniques de Pseudopotential, Toulouse, du 5 au 9 Octobre 1981.

16 M.J. Frisch, J.A. Pople and J.S. Binkley, J. Chem. Phys., 80 (1984) 3265.

17 S. Huzinaga, Gaussian Basis Sets for Molecular Calculations, Elsevier, Amsterdam, 1984, p. 17.

18 A $4 s, 4 p$ basis set resulting from a least-squares fit to a $15 s, 15 p$ basis yielded comparable or only a little better results [12]. Therefore they were not presented here.

19 PSATOM [15] modified by U. Wedig, Universität Stuttgart.

20 I.P. Grant, B.J. McKenzie, P.H. Norrington, D.F. Mayers and N.C. Pyper, Comput. Phys. Commun., 21 (1980) 207.

21 L.E. McMurchie, S.T. Elbert, S.R. Langhoff and E.R. Davidson, NRCC Program No. QC04.

22 M.J.S. Dewar and W. Thiel, J. Am. Chem. Soc., 99 (1977) 4899.

23 J.J.P. Stewart and F.J. Seiler, QCPE Program No. 486.

24 We have done test calculations where we successively replaced parts of the STO-3G basis set by the corresponding parts of a larger contracted basis set and compared this with the pseudopotential calculations. The description of the core had no influence on the geometry. The good geometry of the STO-3G calculation is due to an error compensation in the valence shell.

25 P. Carsky and M. Urban, Ab Initio Calculations, Springer, Berlin, 1980, p. 135.

26 K.E. Edgecombe and R.J. Boyd, Can. J. Chem., 61 (1983) 45.

27 R.A. Whiteside, J.S. Binkley, R. Krishnan, D.J. DeFrees, H.B. Schlegel and J.A. Pople, Carnegie-Mellon Quantum Chemistry Archive, Pittsburgh, PA, U.S.A., 1980.

28 D.J. DeFrees, K. Raghavachari, H.B. Schlegel and J.A. Pople, J. Am. Chem. Soc., 104 (1982) 5576.

29 G. Tarrago, M. Dang-Nhu, G. Poussigue, J. Mol. Spectrosc., 49 (1974) 322.

30 J.L. Duncan, D.C. McKean, P.D. Mallinson, R.D. McCulloch, J. Mol. Spectrosc., 46 (1973) 232.

31 J. Duncan, J. Mol. Struct., 6 (1970) 447.

32 J.N. Ghosh, R. Trambarulo and W. Gordy, J. Chem. Phys., 20 (1952) 60 '.

33 L.E. Sutton, D. Phil, Tables of Interatomic Distances and Configuration in Molecules and Ions, The Chemical Society, London, 1965.

34 M.-H. Whangbo and K.R. Stewart, Inorg. Chem., 21 (1982) 1720.

35 W.J. Pietro, M.M. Francl, W.J. Hehre, D.J. DeFrees, J.A. Pople and J.S. Binkley, J. Am. Chem. Soc., 104 (1982) 5039.

36 L.S. Bartell, J. Chem. Phys., 32 (1960) 832.

37 I.Y. Wang, C.O. Britt, A.H. Cowley and J. Boggs, J. Chem. Phys., 48 (1968) 812. 